Discussion Paper No. 527

INTERNATIONAL SPILLOVER OF

ECONOMIC FLUCTUATIONS:

A DYNAMIC OPTIMIZATION APPROACH

\author{
Yoshiyasu Ono
}

February 2001

The Institute of Social and Economic Research Osaka University

6-1 Mihogaoka, Ibaraki, Osaka 567-0047, Japan 


\title{
International Spillover of Economic Fluctuations: A Dynamic Optimization Approach
}

\author{
by \\ Yoshiyasu Ono* \\ Osaka University
}

\begin{abstract}
After the 1990 Japanese stock market crash the Japanese economy began to stagnate whereas the U.S. economy began to expand, yet the yen tended to appreciate against the dollar. Such a phenomenon is difficult to explain in conventional models. This paper examines its mechanism using a two-country dynamic model that accommodates a liquidity trap and unemployment. If the marginal utility of consumption relative to that of liquidity declines in a country, its current account improves, which appreciates the home currency against the foreign currency. Consequently, home products lose competitiveness, causing home employment to decrease and foreign employment to increase.
\end{abstract}

JEL classification: F41, F42

Keywords: persistent unemployment, exchange rate, current account

Address: Institute of Social and Economic Research, Osaka University, 6-1, Mihogaoka, Ibaraki, Osaka, 567-0047, JAPAN

E-mail: ono@iser.osaka-u.ac.jp

* This paper is based on a special lecture given to the 2000 spring meeting of the Japanese Economic Association held at Yokohama City University. The author is indebted to Ryo Horii, Shinsuke Ikeda, and Akihisa Shibata for their valuable comments. 


\section{Introduction}

Since 1990 Japan has been in the worst stagnation after World War II. People do not consume enough to attain full employment. Investment does not increase although the Bank of Japan expands the money supply and keeps the official discount rate to be almost zero. This seems a typical Keynesian shortage of demand that occurs under a liquidity trap. By contrast, the U.S. then started to grow and now is in a historically rare boom. Such international asymmetry in business activity is not an exceptional phenomenon under the regime of flexible exchange rates and free international capital transactions. Indeed, for several years after Japan's total capital liberalization in the mid-1980s Japan boomed and people believed that it would last forever while the U.S. stagnated. In the late 1990s their positions were just reversed.

In this period it was also observed that the Japanese yen tended to depreciate against the U.S. dollar when Japan's business activity improved relatively to the U.S.'s (1987-1990 and 1995-1997), and that the yen tended to appreciate when Japan's business activity worsened (1990-1995, 1997-2000). It implies that the more a country stagnates, the more its currency appreciates against the other, contrary to what is usually insisted. ${ }^{1}$

Using a two-country two-commodity dynamic model with optimizing agents that accommodates a liquidity trap, this paper explores a mechanism behind such international asymmetry in business activity and appreciation of the stagnant country's currency.

Most models of international macro-dynamics, such as Frenkel and Razin (1985), Devereux and Shi (1991), Turnovsky and Sen (1991), Ghosh (1992), Ikeda and Ono (1992), and Ono and Shibata (1992), focus on the market equilibrium path. They assume that all prices and wages perfectly adjust so that demand always equals supply in all markets, and thereby intrinsically ignore the possibility of an effective-demand shortage. Only supply-side inefficiencies are emphasized as causes of a decrease in national income.

Along this line, when Japan was booming in the 1980s, Japanese supply-side factors, such as the banking system, the management system and industrial policy, were taken to be the best in the world. In contrast, since Japan's stagnation started in the early 1990s, they have been considered to be the worst. However, it is dubious to attribute the present Japanese stagnation

\footnotetext{
${ }^{1}$ In a standard neoclassical framework with money a decrease in a country's output raises its commdity price, which causes its currency to depreciate against the other's.
} 
to those supply-side factors since their behavioral patterns do not essentially change between the two periods. It should rather be attributed to an effective-demand shortage. Policy makers notice it and try various demand-side policies. When doing so, they still rely on the MundellFleming model or its variations, e.g. Dornbusch $(1980),{ }^{2}$ in spite of the absence of microeconomic foundations since an effective-demand shortage is not treated in neoclassical models.

Unfortunately, however, international asymmetry in business activity is rather unusual even in the Mundell-Fleming framework. In that framework a boom should be transmitted from a country to the other since the booming country imports a lot, causing the other country's employment to increase. In reality, the U.S. booms and imports a lot from Japan; nevertheless the Japanese economy badly stagnates.

Recently, various models of exchange-rate dynamics with sticky prices/wages and optimizing agents have developed. Using a period-analysis framework with monopolistic competition, Obstfeld and Rogoff (1995), Christiano, Eichenbaum and Evance (1997), and Hau (2000) assume that prices/wages can be modified only at the beginning of each period and examine the effects of macroeconomic policies within a period. There are also some attempts to analyze the dynamics of a competitive world economy with either price/wage rigidity (Fender, 1986; Rodrick, 1987) or sluggishness (Ploeg, 1993) in a one-commodity setting.

A common feature of these models is that a market equilibrium is eventually reached as prices/wages adjust, and thus they focus on a short-run fluctuation caused by a macroeconomic policy. This paper, in contrast, analyzes an effective-demand shortage and unemployment as steady-state phenomena. ${ }^{3}$ Households and firms are assumed to behave competitively in a two-country two-commodity economy, and yet unemployment is shown to remain in the steady state although prices and wages keep declining. ${ }^{4}$ There are two key assumptions in this paper; (i) liquidity preference that generates a liquidity trap and (ii) sluggish nominal wage

\footnotetext{
${ }^{2}$ For this type of model see also Buiter and Miller (1981,1982), Kawai (1985), Gerlach (1989), Natividad and Stone (1990), and Lyons (1990).

${ }^{3}$ In a closed economy setting Ono $(1994,2001)$ presents a dynamic optimization model that accommodates persistent unemployment. The model of this paper is an extention of it into an international context.

${ }^{4}$ By assuming some permanent imperfections that prevent prices/wages from attaining their respective market equilibrium levels, such as the monopolistic behavior of firms or laborers and imperfect information, the New Keynesian approach obtains a non-Walrasian equilibrium that accommodates a demand-supply discrepancy in some market(s). In contrast, we here assume away any permanent imperfection of markets.
} 
adjustment. Adjustments in all the other markets, viz. the commodity market, the money market, and the interest-bearing asset market, are assumed to be perfect.

Assumption (ii) is imposed in order to allow disequilibrium to occur in the labor market; otherwise the possibility of unemployment is intrinsically avoided. Note that this assumption does not eliminate the possibility of full employment in the steady state. In fact, without assumption (i) full employment eventually obtains even under assumption (ii), as in the above-mentioned conventional models. Once assumption (i) is imposed, however, a liquidity trap occurs and then full employment can never be reached under assumption (ii). In the steady state of this economy the international asymmetry in business activity and the appreciation of the stagnant country's currency, mentioned at the outset of this section, are shown to occur.

This paper is organized as follows. Section 2 presents an intuition behind the logic of this paper. Section 3 exhibits the basic structure of the model. The condition for a liquidity trap and persistent unemployment to occur is shown in section 4. Section 5 focuses on the unemployment steady state and examines the effect of a change in liquidity preference on the two countries' employment. An increase in liquidity preference is shown to reduce home employment, increase foreign employment, and cause the home currency to appreciate against the foreign one. Effects of a productivity increase and fiscal spending are also discussed. Finally, section 6 summarizes and concludes.

\section{A Sketch}

Before starting a formal analysis, I intuitively explain the mechanism for international asymmetry in business activity and appreciation of the stagnant country's currency that will be presented in this paper.

An economy with two countries, $\mathrm{J}$ and $\mathrm{A}$, is considered. The currency of country $\mathrm{J}$ is called 'yen', and that of country A 'dollar'. The product of country $\mathrm{J}$ is commodity 1 and that of country A is commodity 2, which are differentiated from each other. Households in the two countries consume both commodities. For simplicity, firms are assumed to use only labor for production and thus there is no investment.

As a result of optimizing household behavior each country's consumption expenditure, $c$ and $c^{*}$, will be shown to have the following functional form:

$$
c=f\left(c^{*}, \omega\right), \quad c^{*}=f^{*}(c, \omega),
$$


where $\omega$ is the relative price of country A's product. Naturally, they satisfy

$$
\partial f / \partial c^{*}>0, \quad \partial f / \partial \omega>0 ; \quad \partial f^{*} / \partial c>0, \quad \partial f^{*} / \partial \omega<0,
$$

i.e., an increase in a country's consumption raises the other country's employment and therefore stimulates its consumption. A rise in the relative price of a country's product lowers its own, and raises the other country's, employment and consumption. From (1) $c$ and $c^{*}$ will be solved as functions of $\omega$ :

$$
c=c(\omega), c^{*}=c^{*}(\omega),
$$

which satisfy

$$
c^{\prime}(\omega)>0, \quad c^{*^{\prime}}(\omega)<0 .
$$

Intuitively, a rise in the relative price of country A's product increases country J's consumption and decreases country A's consumption.

Given these functions, relative price $\omega$ is determined so that the current account takes its fundamental level. This level is zero in the present model since both countries are assumed to have the same subjective discount rate. Current account $B^{P}$ is

$$
B^{P}=B^{P}(\omega)=r b+p_{1}(\omega) c_{1}^{*}\left(c^{*}(\omega), \omega\right)-p_{2}(\omega) c_{2}(c(\omega), \omega),
$$

where $b$ is country J's real foreign asset holding, $r$ the real interest rate, and $p_{i}(\omega)$ the real price of commodity $i(i=1,2)$, which satisfies $p_{2}(\omega)=\omega p_{1}(\omega) . c_{1}^{*}\left(c^{*}, \omega\right)$ and $c_{2}(c, \omega)$ respectively stand for country A's demand for commodity 1 (viz. the Japanese product) and country J's demand for commodity 2 (viz. the U.S. product), which are functions of each country's own consumption expenditure and relative price $\omega . B^{P}$ is assumed to satisfy

$$
\mathrm{d} B^{P} / \mathrm{d} \omega>0 \text { (the Marshall-Lerner condition). }
$$

Once $\omega$ is determined so that $B^{P}$ defined by (4) is zero, $c$ and $c^{*}$ are determined according to (3).

The movement of nominal exchange rate $\varepsilon$ [yen/dollar] is governed by the no-arbitrage condition between the home and foreign interest rates:

$$
R=\dot{\varepsilon} / \varepsilon+R^{*},
$$

where $R$ and $R^{*}$ are respectively the yen and dollar rates of interest. $R$ (or $R^{*}$ ) will be shown to be an increasing function with respect to $c$ ( or $c^{*}$ ).

$$
R=R(c), R^{\prime}(c)>0 ; R^{*}=R^{*}\left(c^{*}\right), R^{*^{\prime}}\left(c^{*}\right)>0 .
$$

In this setup, international asymmetry in business activity and appreciation of the stagnant country's currency will obtain. Namely, if country J's desire to consume declines and thus $c(\omega)$ autonomously shifts downward, $B^{P}(\omega)$ given by (4) improves. In order to recover the previous current-account level the yen appreciates under the Marshall-Lerner condition, causing $\omega$ to 
decrease. It deteriorates the competitiveness of country J's product and improves that of country A's product. Therefore, consumption and employment decrease in country $\mathrm{J}$ whereas they increase in country A. In this way, a decline in country J's desire to consume leads to yen appreciation, causing country J's business activity to deteriorate and country A's business activity to improve.

In this state the nominal interest rate declines in country $\mathrm{J}$ and rises in country A, as obtained from (7). Thus, from (6) $\dot{\varepsilon} / \varepsilon$ decreases, which implies that the rate of yen appreciation rises.

In the following analysis, equations (1), (3), (4), and (7) are derived from each agent's optimization behavior and market adjustments.

\section{The Model}

Firms: The firm sectors of the two countries have linear-homogeneous technology:

$$
y_{1}=\theta_{1} l, \quad y_{2}^{*}=\theta_{2} l^{*},
$$

where $y_{1}$ and $y_{2}^{*}$ represent each country's output, and $l$ and $l^{*}$ labor input. Input-output coefficient $\theta_{1}$ and $\theta_{2}$ are assumed to be constant. The nominal prices of the two commodities in the two countries are respectively

$$
\begin{aligned}
& \text { commodity 1: } \quad P_{1} \text { yen, } \quad P_{1} / \varepsilon \text { dollars, } \\
& \text { commodity 2: } \varepsilon P_{2} * \text { yen, } \quad P_{2} * \text { dollars. }
\end{aligned}
$$

Given (8) and (9) both firms decide labor demand so as to maximize profits:

$$
\left(\theta_{1} P_{1}-W\right) l, \quad\left(\theta_{2} P_{2}^{*}-W^{*}\right) l^{*},
$$

where $W$ and $W^{*}$ denote the nominal wage in each country. Therefore, labor demand satisfies

$$
\begin{array}{ccl}
\text { Country } \mathrm{J}: & l=\infty & \text { if } \theta_{1} P_{1}>W, \\
& 0<l<\infty & \text { if } \theta_{1} P_{1}=W, \\
& l=0 & \text { if } \theta_{1} P_{1}<W . \\
\text { Country A: } & l^{*}=\infty & \text { if } \theta_{2} P_{2} * W^{*}, \\
& 0<l^{*}<\infty & \text { if } \theta_{2} P_{2} * W^{*}, \\
l^{*}=0 & \text { if } \theta_{2} P_{2} * W^{*} .
\end{array}
$$


Households: A representative household of each country consumes both commodities, and holds two assets, the home currency and the interest-bearing asset. For simplicity, the interest-bearing asset is assumed to be an index bond. The household does not hold the foreign currency since the foreign currency yields neither interest nor liquidity and hence is inferior to the home currency and to the interest-bearing asset.

The instantaneous utility of the representative household in each country is assumed to be

$$
u\left(c_{1}, c_{2}\right)+v(m), \quad u^{*}\left(c_{1}^{*}, c_{2}^{*}\right)+v^{*}\left(m^{*}\right),
$$

where $v(m)$ satisfies

$$
v^{\prime}(m)>0, \quad v^{\prime \prime}(m)<0 ; \quad v^{* \prime}\left(m^{*}\right)>0, \quad v^{* \prime \prime}\left(m^{*}\right)<0 .
$$

In order for the general price level to be a function of only the prices of the two commodities, $u\left(c_{1}, c_{2}\right)$ and $u^{*}\left(c_{1}^{*}, c_{2}^{*}\right)$ are assumed to be the following CES functions:

$$
u\left(c_{1}, c_{2}\right)=(1 / \sigma) \ln \left(\kappa_{1} c_{1}{ }^{\sigma}+\kappa_{2} c_{2}{ }^{\sigma}\right), u^{*}\left(c_{1}{ }^{*}, c_{2}{ }^{*}\right)=(1 / \sigma) \ln \left(\kappa_{1} c_{1}{ }^{\sigma}+\kappa_{2} c_{2}{ }^{* \sigma}\right) .
$$

In this case general price levels $P$ and $P^{*}$, and real prices of the two commodities $p_{1}(\omega)$ and $p_{2}(\omega)$, are respectively

$$
\begin{gathered}
P=1 /\left[\kappa_{1}{ }^{1 /(1-\sigma)} P_{1}{ }^{-\sigma /(1-\sigma)}+\kappa_{2}{ }^{1 /(1-\sigma)}\left(\varepsilon P_{2}{ }^{*}\right)^{-\sigma /(1-\sigma)}\right]^{(1-\sigma) / \sigma}, \\
P^{*}=1 /\left[\kappa_{1}{ }^{1 /(1-\sigma)}\left(P_{1} / \varepsilon\right)^{-\sigma /(1-\sigma)}+\kappa_{2}{ }^{1 /(1-\sigma)} P_{2}{ }^{*-\sigma /(1-\sigma)}\right]^{(1-\sigma) / \sigma}, \\
p_{1}(\omega)\left(\equiv P_{1} / P\right)=\left[\kappa_{1}{ }^{1 /(1-\sigma)}+\kappa_{2}{ }^{1 /(1-\sigma)} \omega^{-\sigma /(1-\sigma)}\right]^{(1-\sigma) / \sigma}, \\
p_{2}(\omega)\left(\equiv P_{2}{ }^{*} / P^{*}\right)=\omega p_{1}(\omega)=\left[\kappa_{1}{ }^{1 /(1-\sigma)} \omega^{\sigma /(1-\sigma)}+\kappa_{2}{ }^{1 /(1-\sigma)}\right]^{(1-\sigma) / \sigma},
\end{gathered}
$$

where relative price $\omega$ is represented by

$$
\omega=\varepsilon P_{2} * / P_{1} .
$$

From the first two equations of (13), $P$ and $P^{*}$ satisfy

$$
P^{*}=P / \varepsilon,
$$

and thus inflation rates $\pi$ and $\pi^{*}$ satisfy

$$
\pi-\dot{\varepsilon} / \varepsilon=\pi^{*} .
$$

Therefore, from the no-arbitrage condition (6)

$$
r=R-\pi=R^{*}-\pi^{*},
$$

which implies the real interest rate to be internationally equal.

Since total asset $a$ (or $a^{*}$ ) consists of home currency $m$ (or $m^{*}$ ) and interest-bearing asset $b$ (or $b^{*}$ ), all measured in real terms, the respective countries' asset constraints are

$$
a=b+m, \quad a^{*}=b^{*}+m^{*} .
$$

Their flow budget equations in real terms are

$$
\dot{a}=r a+w x-c-R m-z, \quad \dot{a}^{*}=r a^{*}+w^{*} x^{*}-c^{*}-R^{*} m^{*}-z^{*},
$$


where $w$ and $w^{*}$ are real wages, $x$ and $x^{*}$ actual labor supplies, and $z$ and $z^{*}$ real lump-sum taxes. ${ }^{5}$ Let each household's labor endowment be normalized to unity, $x$ and $x^{*}$ are given by

$$
x=\min (1, l), \quad x^{*}=\min \left(1, l^{*}\right) .
$$

Representative households maximize

$$
U=\int_{0}^{\infty}\left(u\left(c_{1}, c_{2}\right)+v(m)\right) \exp (-\rho t) d t, \quad U^{*}=\int_{0}^{\infty}\left(u^{*}\left(c_{1}^{*}, c_{2}^{*}\right)+v^{*}\left(m^{*}\right)\right) \exp (-\rho t) d t,
$$

subject to (17) and (18), where both households are assumed to have the same subjective discount rate $\rho$. The first-order optimal conditions of this problem reduce to

$$
\begin{gathered}
p_{1}(\omega) c_{1}=\delta(\omega) c, \quad p_{2}(\omega) c_{2}=[1-\delta(\omega)] c, \\
p_{1}(\omega) c_{1}^{*}=\delta(\omega) c^{*}, \quad p_{2}(\omega) c_{2}^{*}=[1-\delta(\omega)] c^{*},
\end{gathered}
$$

and

$$
\rho+\dot{c} / c+\pi=R=v^{\prime}(m) c, \quad \rho+\dot{c}^{*} / c^{*}+\pi^{*}=R^{*}=v^{* \prime}\left(m^{*}\right) c^{*} .
$$

where $c, c^{*}$, and $\delta(\omega)$ are

$$
\begin{gathered}
c=p_{1} c_{1}+p_{2} c_{2}, \quad c^{*}=p_{1} c_{1}{ }^{*}+p_{2} c_{2}{ }^{*}, \\
\delta(\omega)=\kappa_{1}{ }^{1 /(1-\sigma)} /\left[\kappa_{1}{ }^{1 /(1-\sigma)}+\kappa_{2}{ }^{1 /(1-\sigma)} \omega^{-\sigma /(1-\sigma)}\right]=1+p_{1}{ }^{\prime}(\omega) \omega / p_{1}(\omega)=p_{2}{ }^{\prime}(\omega) \omega / p_{2}(\omega), \\
1>\delta(\omega)>0, \delta^{\prime}(\omega)=[\sigma /(1-\sigma)][\delta(1-\delta) / \omega]>0 .
\end{gathered}
$$

The transversality conditions are

$$
\lim _{t \rightarrow \infty} \lambda(t) a(t) \exp (-\rho t)=0, \quad \lim _{t \rightarrow \infty} \lambda *(t) a^{*}(t) \exp (-\rho t)=0,
$$

where $\lambda$ and $\lambda *$ are co-state variables for $a$ and $a^{*}$ respectively.

Governments: Country J's government imposes lump-sum tax $z$ to finance fiscal spending on the two commodities $g_{1}$ and $g_{2}$. For simplicity, nominal money stock $M$ is assumed to be constant. In this case its budget constraint is

$$
z=p_{1} g_{1}+p_{2} g_{2} \text {. }
$$

Since effects of country A's policies can symmetrically be treated, its fiscal spending $g_{1}{ }^{*}$ and $g_{2}{ }^{*}$ and tax $z^{*}$ are assumed to be zero and its money supply $M^{*}$ to be constant.

\footnotetext{
${ }^{5}$ The nominal flow budget equation is$$
\dot{A}=W x+R P b-P c-P z
$$

where $A(=P a)$ represents total asset holdings measured in terms of yen. Equation (18) is derived from this equation and (17). 
Market adjustments: The two commodity markets and the interest-bearing asset market are internationally integrated and perfectly adjust so that demand and supply always match. Money market adjustment is also perfect in each country. In contrast, the labor market is internationally segmented and nominal wage adjustment is assumed to be sluggish. ${ }^{6}$

Owing to perfect adjustment of the stock markets, at any point in time

the money markets: $\quad M / P=m, \quad M^{*} / P^{*}=m^{*}$,

the international asset market: ${ }^{7} \quad b+b^{*}=0$.

Since commodity market adjustment is also assumed to be perfect,

$$
\begin{gathered}
\theta_{1} x=c_{1}+g_{1}+c_{1}^{*}=\delta(\omega)\left(c+c^{*}\right) / p_{1}(\omega)+g_{1}, \\
\theta_{2} x^{*}=c_{2}+g_{2}+c_{2} *=[1-\delta(\omega)]\left(c+c^{*}\right) / p_{2}(\omega)+g_{2} .
\end{gathered}
$$

In contrast, each nominal wage adjusts sluggishly according to each unemployment rate: ${ }^{8}$

$$
\dot{W} / W=\alpha(l-1), \quad \dot{W}^{*} / W^{*}=\alpha^{*}\left(l^{*}-1\right) .
$$

From (11), if $\theta_{1} P_{1}>W, l=\infty$ and thus $W$ immediately increases to $\theta_{1} P_{1}$ even under the sluggish wage adjustment in (27). If $\theta_{1} P_{1}<W, l=0$ and hence commodity supply is zero, causing $P_{1}$ to jump upward because of perfect adjustment of $P_{1}$. In this way $\theta_{1} P_{1}$ immediately becomes equal to $W$ anyway. Then $l$ can take any finite value, and hence it is set to be the level under which production matches demand. After such initial adjustment $P_{1}$ and $W$ in parallel follow (27) in which $x$ replaces $l$. The movements of $P_{2}{ }^{*}$ and $W^{*}$ analogously obtain. Thus, at any point in time

$$
\begin{gathered}
p_{1} \theta_{1}=w(=W / P), \quad p_{2} \theta_{2}=w^{*}\left(=W^{*} / P^{*}\right), \\
\dot{P}_{1} / P_{1}=\dot{W} / W=\alpha(x-1), \quad \dot{P}_{2} * / P_{2} *=\dot{W}^{*} / W^{*}=\alpha^{*}\left(x^{*}-1\right) .
\end{gathered}
$$

From (29) and the definition of $\delta(\omega)$ given in $(21), \pi$ and $\pi^{*}$ are

$$
\pi=\alpha(x-1)+[1-\delta(\omega)] \dot{\omega} / \omega, \quad \pi^{*}=\alpha^{*}\left(x^{*}-1\right)-\delta(\omega) \dot{\omega} / \omega .
$$

The foreign-asset dynamics obtains from (18), (23), and (28).

$$
\dot{b}=r b+p_{1} \theta_{1} x-\left(c+p_{1} g_{1}+p_{2} g_{2}\right), \quad \dot{b}^{*}=r b^{*}+p_{2} \theta_{2} x^{*}-c^{*} .
$$

Note that the two equations in (31) imply each other because of (25) and (26).

\footnotetext{
${ }^{6}$ As stated in the introduction, this assumption is imposed in order to allow disequilibrium to occur in the labor market; otherwise the possibility of unemployment is intrinsically avoided. Note that under this assumption the possibility of the full employment steady state is not eliminated. In fact, section 4 obtains the full employment steady state under it.

${ }^{7}$ Because of Walras's law for stock variables, (25) is valid if (24) holds.

${ }^{8}$ See Roberts (1995) for variations of this type of sluggish adjustment called new Keynesian Phillips curves.
} 


\section{Steady States with Full Employment and Unemployment}

This section explores the condition under which unemployment occurs in the steady state. In the steady state $c$ stays constant, and thus from (20)

$$
r=\rho .
$$

For simplicity, fiscal spending is assumed to be zero in this section.

$$
g_{1}=g_{2}=0 .
$$

Since $b$ and $b^{*}$ stay constant in the steady state, ${ }^{9}$ from (31) and (32),

$$
\dot{b}=\rho b+p_{1} \theta_{1} x-c=0, \quad \dot{b}^{*}=\rho b^{*}+p_{2} \theta_{2} x^{*}-c^{*}=0 .
$$

From (21) and (26), $\dot{b}$ in (33) is rewritten as

$$
\dot{b}=\rho b+p_{1}(\omega) c_{1}^{*}-p_{2}(\omega) c_{2},
$$

which represents $B^{P}$ in (4).

If full employment obtains in this state,

$$
x=1 .
$$

Therefore, from (13), (19), (26), and (33),

$$
\begin{gathered}
\omega=\left(\kappa_{2} / \kappa_{1}\right)\left(\theta_{1} / \theta_{2}\right)^{(1-\sigma)}, \\
c=\kappa_{1} \theta_{1}{ }^{\sigma}\left[\kappa_{1} \theta_{1}{ }^{\sigma}+\kappa_{2} \theta_{2}{ }^{\sigma}\right]^{(1-\sigma) / \sigma}+\rho b, \quad c^{*}=\kappa_{2} \theta_{2}{ }^{\sigma}\left[\kappa_{1} \theta_{1}{ }^{\sigma}+\kappa_{2} \theta_{2}{ }^{\sigma}\right]^{(1-\sigma) / \sigma}-\rho b .
\end{gathered}
$$

Note that the steady-state levels of real variables are independent of the levels of monetary variables. Substituting (30) and (34) into (20) gives the conditions for $m$ and $m^{*}$ to satisfy in the steady state.

$$
\begin{gathered}
v^{\prime}(m)\left\{\kappa_{1} \theta_{1}{ }^{\sigma}\left[\kappa_{1} \theta_{1}{ }^{\sigma}+\kappa_{2} \theta_{2}{ }^{\sigma}\right]^{(1-\sigma) / \sigma}+\rho b\right\}=\rho, \\
v^{* \prime}\left(m^{*}\right)\left\{\kappa_{2} \theta_{2}{ }^{\sigma}\left[\kappa_{1} \theta_{1}{ }^{\sigma}+\kappa_{2} \theta_{2}{ }^{\sigma}\right]^{(1-\sigma) / \sigma}-\rho b\right\}=\rho .
\end{gathered}
$$

Now suppose the possibility of a liquidity trap. Liquidity demand functions imply the relationship between $R$ and $m$ for a given $c$ and that between $R^{*}$ and $m^{*}$ for a given $c^{*}$ derived from (20).

$$
R=v^{\prime}(m) c, \quad R^{*}=v^{* \prime}\left(m^{*}\right) c^{*} .
$$

Since $v^{\prime \prime}(m)<0$ and $v^{* \prime \prime}\left(m^{*}\right)<0, R$ (or $R^{*}$ ) is negatively related to $m$ (or $m^{*}$ ). If $v^{\prime}(m)$ and $v^{*^{\prime}}\left(m^{*}\right)$ have positive lower bounds, ${ }^{10}$

\footnotetext{
${ }^{9}$ Otherwise, the transversality condition is not satisfied.
} 


$$
v^{\prime}(\infty)=\beta>0, \quad v^{* \prime}(\infty)=\beta^{*}>0,
$$

$R$ (or $R^{*}$ ) asymptotically approaches a constant level $\beta c\left(\right.$ or $\beta^{*} c^{*}$ ) and eventually a liquidity trap occurs, as illustrated in figure 1.

In the presence of a liquidity trap, solutions for $m$ and $m^{*}$ may not exist. In fact, from (35),

$$
\begin{aligned}
& \rho b \geq \rho / \beta-\kappa_{1} \theta_{1}{ }^{\sigma}\left(\kappa_{1} \theta_{1}{ }^{\sigma}+\kappa_{2} \theta_{2}{ }^{\sigma}\right)^{(1-\sigma) / \sigma} \Leftrightarrow \text { the } m \text { does not exist. } \\
& \rho b \leq \kappa_{2} \theta_{2}{ }^{\sigma}\left(\kappa_{1} \theta_{1}{ }^{\sigma}+\kappa_{2} \theta_{2}{ }^{\sigma}\right)^{(1-\sigma) / \sigma}-\rho / \beta^{*} \Leftrightarrow \text { the } m^{*} \text { does not exist. }
\end{aligned}
$$

If the $m$ (or $m^{*}$ ) that satisfies (35) does not exist, the left-hand side of (35) exceeds its righthand side for any $m$ (or $m^{*}$ ), implying that the desire for saving exceeds that for consumption if the consumption level is so high as to attain full employment. From (38), at least one of the two countries faces unemployment if

$$
\left[\kappa_{1} \theta_{1}{ }^{\sigma}+\kappa_{2} \theta_{2}{ }^{\sigma}\right]^{1 / \sigma} \geq\left(1 / \beta+1 / \beta^{*}\right) \rho .
$$

In the case where both conditions in (38) hold and hence the two countries face a shortage of demand, what steady state obtains? In this state prices and wages continue to decline and $v^{\prime}(m)$ and $v^{*^{\prime}}\left(m^{*}\right)$ converge to $\beta$ and $\beta^{*}$ respectively. Therefore, from (20), (26) and (30) in which $c, c^{*}$ and $\omega$ stay constant, the state satisfies

$$
\begin{gathered}
\beta c=\rho+\alpha(x-1), \quad x=\delta(\omega)\left(c+c^{*}\right) /\left[p_{1}(\omega) \theta_{1}\right], \\
\beta^{*} c^{*}=\rho+\alpha^{*}\left(x^{*}-1\right), \quad x^{*}=[1-\delta(\omega)]\left(c+c^{*}\right) /\left[p_{2}(\omega) \theta_{2}\right],
\end{gathered}
$$

from which

$$
\begin{gathered}
c=f\left(c^{*}, \omega\right)=\left[\rho-\alpha+\alpha c^{*} \delta(\omega) /\left(p_{1} \theta_{1}\right)\right] /\left[\beta-\alpha \delta(\omega) /\left(p_{1} \theta_{1}\right)\right], \\
c^{*}=f^{*}(c, \omega)=\left[\rho-\alpha^{*}+\alpha^{*} c(1-\delta(\omega)) /\left(p_{2} \theta_{2}\right)\right] /\left[\beta^{*}-\alpha^{*}(1-\delta(\omega)) /\left(p_{2} \theta_{2}\right)\right] .
\end{gathered}
$$

These are $f\left(c^{*}, \omega\right)$ and $f^{*}(c, \omega)$ given in $(1)$.

Figure 2 represents the two curves in (40) for a given level of $\omega$. Note that the figure is illustrated so as to satisfy the following properties: (i) $c$ (or $\left.c^{*}\right)$ is positive even if $c^{*}$ (or $c$ ) is zero, (ii) an increase in $c^{*}$ (or $c$ ) raises $c$ (or $c^{*}$ ) (a Mundell-Fleming feature), and (iii) intersection point $\mathrm{E}$ exists. They are indeed satisfied under the following conditions: ${ }^{11}$

10 This property is empirically shown by Ono (1994, chap.3), and more extensively by Ono, Ogawa, and Yoshida (1998) using both a parametric and a non-parametric approach. Theoretically, this property obtains in Veblen's framework (1899) where households care about 'status'. In particular, if $v(m)$ is replaced by $v(m-\bar{m})$, where $\bar{m}$ implies the social average of $m, v^{\prime}(m-\bar{m})$ stays to be fixed at $v^{\prime}(0)$ as $m$ expands since $m$ always equals $\bar{m}$ in the present setting. Thus, let this value $\beta$, the following argument holds. See Clark and Oswald (1998) for an extensive survey on the 'status' literature.

${ }^{11}$ The last two conditions in (41) must be satisfied in order for the present dynamics to be saddle-path stable, as is shown in the appendix. The first condition is found to be valid, e.g., in the case where the two countries are fully symmetric. 


$$
A=1-\alpha \delta /\left(\beta p_{1} \theta_{1}\right)-\alpha^{*}(1-\delta) /\left(\beta^{*} p_{2} \theta_{2}\right)>0, \quad \rho>\alpha, \quad \rho>\alpha^{*} .
$$

At intersection point $\mathrm{E}$ in figure $2, c$ and $c^{*}$ are obtained as functions of $\omega$, which represent $c(\omega)$ and $c^{*}(\omega)$ given by (3). Thus, from (39) and (40), $\dot{b}$ in (33) is rewritten as

$$
\dot{b}=\left\{\left[\left(\rho-\alpha^{*}\right) \delta / \beta^{*}\right]\left[1-\alpha /\left(\beta p_{1} \theta_{1}\right)\right]-[(\rho-\alpha)(1-\delta) / \beta]\left[1-\alpha^{*} /\left(\beta^{*} p_{2} \theta_{2}\right)\right]\right\} / A+\rho b .
$$

This function is assumed to satisfy

$$
\text { the Marshall-Lerner condition: } \quad \partial \dot{b} / \partial \omega>0,
$$

as stated in (5). In fact, if $\sigma$ is close to 1 and hence the two commodities are sufficiently substitutable to each other, this condition holds. ${ }^{12}$ Relative price $\omega$ takes the value at which $\dot{b}$ is zero, and then the steady state obtains. ${ }^{13}$

$$
\dot{b}=0 \text {. }
$$

Once $\omega$ is thus determined, from (40) $c$ and $c^{*}$ obtain. From (36), in this state $R$ and $R^{*}$ are

$$
R=\beta c, \quad R^{*}=\beta^{*} c^{*},
$$

which represent $R(c)$ and $R^{*}\left(c^{*}\right)$ in (7). Therefore, the covered interest parity defined by (6) is rewritten as

$$
\dot{\varepsilon} / \varepsilon=\beta c-\beta^{*} c^{*} .
$$

In this steady state $x$ and $x^{*}$ are smaller than 1, and thus all nominal prices and wages continue to decline and $m$ and $m^{*}$ continue to expand. Nevertheless, the two transversality conditions in (22) hold since from (24) and (39)

$$
\dot{m} / m=-\pi=\rho-\beta c<\rho, \quad \dot{m}^{*} / m^{*}=-\pi^{*}=\rho-\beta^{*} c^{*}<\rho .
$$

Note that persistent stagnation occurs not because relative prices and wages are set to be different from those in the full-employment equilibrium but because a liquidity trap creates a shortage of consumption as a whole. In fact, (28) holds regardless of whether full employment realizes or not, implying that each country's wage relative to the price of its home product in the full-employment steady state is the same as that in the unemployment steady state. Particularly in the symmetric case, all real prices and wages are exactly the same in the two cases. Nevertheless, persistent stagnation occurs.

\footnotetext{
${ }^{12}$ In the appendix it is shown when this conditon is valid.

${ }^{13}$ See the appendix for the stablity of the dynamics. Needless to say, (44) is valid since the two countries are assumed to have the same subjective discount rate $\rho$.
} 


\section{Comparative Dynamics}

This section focuses on the case where both countries face unemployment, and examines how an increase in country J's liquidity preference, productivity, the wage adjustment speed, or fiscal spending on each commodity affects consumption and employment in the two countries.

In the presence of fiscal spending the two equations of (40) change to

$$
\begin{aligned}
c & =f\left(c^{*}, \omega ; g_{1}, \alpha, \theta_{1}, \beta\right) \\
& =\left[\rho-\alpha+\alpha c^{*} \delta(\omega) /\left(p_{1} \theta_{1}\right)+\alpha g_{1} / \theta_{1}\right] /\left[\beta-\alpha \delta(\omega) /\left(p_{1} \theta_{1}\right)\right], \\
c^{*} & =f^{*}\left(c, \omega ; g_{2}\right) \\
& =\left[\rho-\alpha^{*}+\alpha^{*} c(1-\delta(\omega)) /\left(p_{2} \theta_{2}\right)+\alpha^{*} g_{2} / \theta_{2}\right] /\left[\beta^{*}-\alpha^{*}(1-\delta(\omega)) /\left(p_{2} \theta_{2}\right)\right],
\end{aligned}
$$

which are illustrated in figure 3. In this figure various Mundell-Fleming implications obtain. For example, an increase in country J's fiscal spending on the home product $\left(g_{1}\right)$ shifts the $f$ curve upward and hence raises both countries' consumption. If it is spent on the foreign product $\left(g_{2}\right)$, the $f^{*}$ curve moves rightwards, causing both countries' consumption to increase. These implications obtain under the assumption that $\omega$ is fixed. However, $\omega$ in fact adjusts so that $\dot{b}$ is zero, as shown by (44), and therefore the effect through a change in $\omega$ must also be taken into account.

In the presence of fiscal spending $\dot{b}$ given in (42) becomes

$$
\begin{aligned}
& \dot{b}=\rho b+\left\{\left[1-\alpha /\left(\beta p_{1} \theta_{1}\right)\right]\left(\rho-\alpha^{*}\right) \delta / \beta^{*}-\left[1-\alpha^{*} /\left(\beta^{*} p_{2} \theta_{2}\right)\right]\right. \\
&\left.\times\left[(\rho-\alpha)(1-\delta) / \beta+\left(1-\delta \alpha /\left(\beta p_{1} \theta_{1}\right)\right) p_{2} g_{2}+(1-\delta) \alpha g_{1} /\left(\beta \theta_{1}\right)\right]\right\} / A .
\end{aligned}
$$

In the neighborhood of the steady state in which $g_{1}=g_{2}=0$ the partial derivatives of this equation satisfy

$$
\partial \dot{b} / \partial \beta>0, \quad \partial \dot{b} / \partial \theta_{1}>0, \quad \partial \dot{b} / \partial \alpha>0, \quad \partial \dot{b} / \partial g_{1}<0, \quad \partial \dot{b} / \partial g_{2}<0 .
$$

These properties and (43) imply

$$
\beta \downarrow, \theta_{1} \downarrow, \alpha \downarrow, g_{1} \uparrow, g_{2} \uparrow \Rightarrow \omega \uparrow .
$$

Figure 4 illustrates these properties.

From (31), in the steady state $x$ and $x^{*}$ are given by

$$
x=\left(c+p_{1} g_{1}+p_{2} g_{2}-\rho b\right) /\left(p_{1} \theta_{1}\right), \quad x^{*}=\left(c^{*}+\rho b\right) /\left(p_{2} \theta_{2}\right) .
$$

Therefore, from (20), (30), (37), and (47), $c$ and $c^{*}$ are

$$
\begin{gathered}
c=\left[\rho-\alpha+\alpha\left(p_{1} g_{1}+p_{2} g_{2}-\rho b\right) /\left(p_{1} \theta_{1}\right)\right] /\left[\beta-\alpha /\left(p_{1} \theta_{1}\right)\right], \\
c^{*}=\left[\rho-\alpha^{*}+\alpha^{*} \rho b /\left(p_{2} \theta_{2}\right)\right] /\left[\beta^{*}-\alpha^{*} /\left(p_{2} \theta_{2}\right)\right] .
\end{gathered}
$$


Estimating the effects on $c$ and $c^{*}$ of various parameters in the neighborhood where

$$
b\left(=-b^{*}\right)=0
$$

yields

$$
\begin{gathered}
\partial c / \partial \omega>0, \partial c / \partial \beta<0, \partial c / \partial \theta_{1}<0, \partial c / \partial \alpha<0, \partial c / \partial g_{1}>0, \partial c / \partial g_{2}>0, \\
\partial c^{*} / \partial \omega<0, \partial c^{*} / \partial \beta=0, \partial c^{*} / \partial \theta_{1}=0, \partial c^{*} / \partial \alpha=0, \partial c^{*} / \partial g_{1}=0, \partial c^{*} / \partial g_{2}=0 .
\end{gathered}
$$

Since (45) still holds in the presence of fiscal spending, from (45) - (48)

$$
\begin{aligned}
\beta \uparrow, \theta_{1} \uparrow, \alpha \uparrow, g_{1} \downarrow, g_{2} \downarrow \\
\quad \Rightarrow c \downarrow, x \downarrow, R \downarrow, \pi \downarrow ; c^{* \uparrow}, x^{*} \uparrow, R^{* \uparrow}, \pi^{* \uparrow ;} \omega \downarrow, \dot{\varepsilon} / \varepsilon \downarrow .
\end{aligned}
$$

These properties are consistent with various phenomena that actually occurred after the 1990 Japanese stock market crash, e.g., Japan's stagnation, the U.S.'s boom, and the yen appreciation. They are formally stated as follows:

Proposition 1: An increase in country J's liquidity preference $(\beta)$ relative to the desire for consumption causes yen to appreciate, and lowers its own, and raises country A's, consumption and employment. The speed of yen appreciation increases.

In order to escape from the historical stagnation Japan attempted to restructure its supply side. Japanese firms cut down employees to raise productivity and more promptly adjusted prices and wages. ${ }^{14}$ However, these attempts worked oppositely -i.e., stagnation worsened. This result is consistent with (49), that is,

Proposition 2: An increase in country J's productivity $\left(\theta_{1}\right)$ or wage adjustment speed $(\alpha)$ causes yen to appreciate, and lowers its own, and raises country A's, consumption and employment. The speed of yen appreciation increases.

The Japanese government also attempted to cut its budget since the public sector's inefficiency was believed to cause the Japanese economy to stagnate. For this purpose it passed a severe fiscal reform bill in 1997. As a result, however, Japan's stagnation became more serious. This result is also consistent with (49), that is,

\footnotetext{
${ }^{14}$ In Japan it was called "Kakaku Hakai" or price destruction.
} 
Proposition 3: A decrease in country J's fiscal spending on either commodity ( $g_{1}$ or $\left.g_{2}\right)$ causes yen to appreciate, and reduces its own consumption and employment. However, it raises country A's consumption and employment because of yen appreciation. It increases the speed of yen appreciation.

To sum up, an exogenous change in a parameter that deteriorates a country's current account causes its currency to depreciate, which in turn increases employment and consumption in the home country but decreases them in the other country. For example, a stimulative policy of country $\mathrm{J}$ worsens its current account, causing the yen to depreciate. Consequently, the international competitiveness of country J's commodity improves and hence employment increases in country $J$ but decreases in country A. Because of a rise in country J's business activity and a decline in country A's, the yen rate of interest increases while the dollar rate decreases. In order to fill the difference between the two countries' nominal interest rates, the appreciation rate of yen declines.

It is worth noting that the above propositions hold only when the steady state accommodates persistent unemployment. If full employment is realized in the steady state, usual neoclassical properties obtain. In fact, in this case neither liquidity preference $\beta$ nor the wage adjustment speed $\alpha$ affects any country's consumption given by (34). An increase in country J's productivity $\theta_{1}$ raises both countries' consumption.

\section{Conclusions}

After the 1990 Japanese stock market crash the Japanese economy began to stagnate whereas the U.S. economy began to recover from stagnation. Nevertheless, the Japanese yen tended to appreciate against the U.S. dollar. Neither neoclassical two-country models nor the conventional Mundell-Fleming model can explain such international asymmetry in business activity and appreciation of the stagnant country's currency. Using a two-country twocommodity dynamic model with optimizing agents that accommodates a liquidity trap, this paper exhibits a mechanism for these phenomena.

In a dynamic optimization framework with a liquidity trap, if people's liquidity preference relative to the marginal utility of consumption exogenously increases in a country, its import decreases and thus its current account improves. Consequently, the home currency appreciates 
against the foreign currency, which causes the competitiveness of the home product to decline. Thus, employment decreases in the home country but increases in the foreign country.

If people's desire to consume relative to their desire to hold liquidity rises, on the contrary, the current account deteriorates and hence the home currency depreciates against the foreign currency. It improves the competitiveness of the home product over the foreign one, and hence employment increases in the home country but decreases in the foreign country. Thus, a country with a smaller desire to consume faces more serious unemployment than the other country, and its currency appreciates against the foreign one.

The above-mentioned property is much in conformity with the Japan-U.S. asymmetry in business activity and the yen appreciation that occurred after the Japanese stock market crash. It is broadly believed that the U.S. boom would positively work on the Japanese economy. However, the U.S. boom causes the U.S. to face a serious current-account deficit, and the Japanese stagnation causes Japan to face a huge surplus, both of which cause the dollar to depreciate against the yen. Consequently, Japanese products lose competitiveness against U.S. products, causing employment to increase in the U.S. and decrease in Japan. In this way, Japan stagnates and the U.S. booms, and nevertheless the yen appreciates against the dollar. Note that it is nothing to do with productivity or technical progress (e.g. IT revolution), as is widely believed, but is caused by the Japan-U.S. difference in people's desire to consume.

Once a country is in such a stagnant state, its fiscal spending worsens its current account, causing the home currency to depreciate. Consequently, the international competitiveness of the home product improves and hence employment rises in the home country but decreases in the foreign country. Thus, a stimulative policy is shown to be effective in the optimization framework. 


\section{Appendix}

For simplicity, this appendix treats the case where the two countries are fully symmetric,

$$
\alpha=\alpha^{*}, \kappa_{1}=\kappa_{2}=\kappa, \quad \beta=\beta^{*}, \quad b(0)=0, \quad \theta_{1}=\theta_{2}, \quad c=c^{*}
$$

and fiscal spending and the monetary expansion rate are zero in the two countries.

\section{Dynamics:}

The local stability of the present dynamics around the stagnation steady state is analyzed. From (6), the time differentiation of (14), (15), (20), (26), and (29),

$$
\begin{aligned}
& \left.\dot{\omega} / \omega=\mathrm{f}^{1}(\omega, c)=\alpha\left(x^{*}-x\right)=2 \alpha c\left(\omega^{-1 /(1-\sigma)}-1\right)\right] /\left\{\theta\left[\kappa\left(1+\omega^{-\sigma /(1-\sigma)}\right)\right]^{1 / \sigma}\right\}, \\
& \dot{c} / c=\mathrm{f}^{2}(\omega, c)=\beta c-2 \alpha c\left(1+\omega^{-(1+\sigma) /(1-\sigma)}\right) /\left[\left(\theta \kappa^{1 / \sigma}\right)\left(1+\omega^{-\sigma /(1-\sigma)}\right)^{(1+\sigma) / \sigma}\right]-(\rho-\alpha), \\
& \dot{b}=\mathrm{f}^{3}(\omega, c, b)=r b+\left(1-\omega^{-\sigma /(1-\sigma)}\right) c /\left(1+\omega^{-\sigma /(1-\sigma)}\right) .
\end{aligned}
$$

The steady state is given by

$$
\omega=1, \quad c=(\rho-\alpha) /\left[\beta-\alpha /\left(2^{(1-\sigma) / \sigma} \theta \kappa^{1 / \sigma}\right)\right], \quad b=0 .
$$

Thus, the characteristic equation is

$$
\left|\begin{array}{ccc}
-\alpha c /\left[(1-\sigma) 2^{(1-\sigma) / \sigma} \kappa^{1 / \sigma} \theta\right]-\lambda & 0 & 0 \\
\left(\partial \mathrm{f}^{2} / \partial \omega\right) c & (\rho-\alpha)-\lambda & 0 \\
\partial \mathrm{f}^{3} / \partial \omega & \partial \mathrm{f}^{3} / \partial c & \rho-\lambda
\end{array}\right|=0
$$

from which the three characteristic solutions are

$$
\rho(>0), \quad \rho-\alpha(>0), \quad-\alpha c /\left[(1-\sigma) 2^{(1-\sigma) / \sigma} \kappa^{1 / \sigma} \theta\right](<0) .
$$

Since $c$ and $\omega$ are jumpable and $b$ is not, the dynamic path is saddle-point stable.

\section{A Sufficient Condition for the Marshall-Lerner Condition to Hold:}

Under (A1), (42) reduces to

$$
\begin{aligned}
\dot{b} & =\left\{\left[1-\alpha /\left(\beta p_{1} \theta_{1}\right)\right] \delta-\left[1-\alpha /\left(\beta p_{2} \theta_{2}\right)\right](1-\delta)\right\}(\rho-\alpha) /(\beta A)+\rho b \\
& =\left\{\omega^{\sigma /(1-\sigma)}-1+\left[\alpha /\left(\beta \theta \kappa^{1 / \sigma}\right)\right]\left(1-\omega^{1 /(1-\sigma)}\right) /\left(1+\omega^{\sigma /(1-\sigma)}\right)^{(1-\sigma) / \sigma}\right\}(1-\delta)(\rho-\alpha) /(\beta A)+\rho b .
\end{aligned}
$$

Differentiating (A3) with respect to $\omega$ and estimating the result in the state given by (A2) yield

$$
\partial \dot{b} /\left.\partial \omega\right|_{\omega=1}=\left[\sigma-\alpha /\left(2^{(1-\sigma) / \sigma} \beta \theta \kappa^{1 / \sigma}\right)\right](\rho-\alpha) /[2(1-\sigma) \beta A] .
$$

Thus, the Marshall-Lerner condition holds if

$$
\sigma-\alpha /\left(2^{(1-\sigma) / \sigma} \beta \theta \kappa^{1 / \sigma}\right)>0, \quad \rho>\alpha .
$$


Under (A1), the two conditions in (38) and (41) reduce to

$$
1 \geq \rho /\left(2^{(1-\sigma) / \sigma} \beta \theta \kappa^{1 / \sigma}\right) \text { and } 1>\alpha /\left(2^{(1-\sigma) / \sigma} \beta \theta \kappa^{1 / \sigma}\right) \text {. }
$$

Thus, as stated in the text, when $\sigma$ is close to 1 , the Marshall Lerner condition holds if the stagnation steady state exists. 


\section{References}

Christiano, Lawrence J., Martin Eichenbaum, and Charles L. Evance, "Sticky Prices and Limited Participation Models of Money: A Comparison,” European Economic Review, vol.41, June 1997, pp.1201-1249.

Clark, Andrew E. and Andrew J. Oswald, "Comparison-Concave Utility and Following Behaviour in Social and Economic Setting," Journal of Public Economics, Vol.70, February 1998, pp.133-155.

Devereux, Michael B. and Shouyong Shi, "Capital Accumulation and the Current Account in a Two-Country Model," Journal of International Economics, Vol.30, February 1991, pp.1-25.

Dornbusch, Rudiger, Open Economy Macroeconomics, Basic Books: New York, 1980.

Fender, John, "Monetary Exchange Rate Policies in an Open Macroeconomic Model with Unemployment and Rational Expectations," Oxford Economic Papers, Vol.38, November 1986, pp.501-515.

Frenkel, Jacob A. and Assaf Razin, “Government Spending, Debt, and International Economic Interdependence,” Economic Journal, Vol.95, September 1985, pp.619-636.

Gerlach, Stefan, "Intertemporal Speculation, Devaluation, and the 'J-Curve'," Journal of International Economics, Vol.27, November 1989, pp.335-345.

Ghosh, Atish R., "Fiscal Policy, the Terms of Trade, and the External Balance," Journal of International Economics, Vol.33, August 1992, pp.105-125.

Hau, Harald, "Exchange Rate Determination: The Role of Factor Price Rigidities and Nontradeables," Journal of International Economics, Vol.50, April 2000, pp.421-447.

Ikeda, Shinsuke and Yoshiyasu Ono, "Macroeconomic Dynamics in a Multi-Country Economy," International Economic Review, Vol.33, August 1992, pp.629-644.

Kawai, Masahiro, "Exchange Rates, the Current Account and Monetary-Fiscal Policies in the Short Run and in the Long Run,” Oxford Economic Papers, Vol.37, September 1985, pp.391-425.

Lyons, Richard K., “Whence Exchange rate Overshooting: Money Stock or Flow?, Journal of International Economics, Vol.29, November 1990, pp.369-384.

Natividad, Fidelina and Joe A. Stone, "A General Equilibrium Model of Exchange Market Intervention with Variable Sterilization,” Journal of International Economics, Vol.29, 
August 1990, pp.133-145.

Obstfeld, Maurice, and Kenneth Rogoff, "Exchange Rate Dynamics Redux,” Journal of Political Economy, vol.103, June 1995, pp.624-660.

Ono, Yoshiyasu, Money, Interest, and Stagnation, Oxford University Press, 1994.

Ono, Yoshiyasu, "A Reinterpretation of Chapter 17 of Keynes's General Theory: Effective Demand Shortage Under Dynamic Optimization," International Economic Review, Vol.42, February 2001, 207-236.

Ono, Yoshiyasu, Kazuo Ogawa, and Atsushi Yoshida, "Liquidity Preference and Persistent Unemployment with Dynamic Optimizing Agents," ISER Discussion Paper, no.461, Osaka University, April 1998.

Ono, Yoshiyasu, and Akihisa Shibata, "Spill-Over Effects of Supply-Side Changes in a TwoCountry Economy with Capital Accumulation," Journal of International Economics, Vol.33 August 1992, pp.127-146.

Ploeg, Frederick van der, "Channels of International Policy Transmission," Journal of International Economics, Vol.34, May 1993, pp.245-267.

Roberts, John M., "New Keynesian Economics and the Phillips Curve," Journal of Money, Credit, and Banking, vol.27, November 1995, pp.975-984.

Rodrick, Dani, “Trade and Capital-Account Liberalization in a Keynesian Economy," Journal of International Economics, Vol.23, August 1987, pp.113-129.

Turnovsky, Stephen J. and Partha Sen, "Fiscal Policy, Capital Accumulation, and Debt in an Open Economy," Oxford Economic Papers, Vol.43, January 1991, pp.1-24.

Veblen, Thorstein, The Theory of the Leisure Class, New York: Modern Library 1934 edn., 1899. 


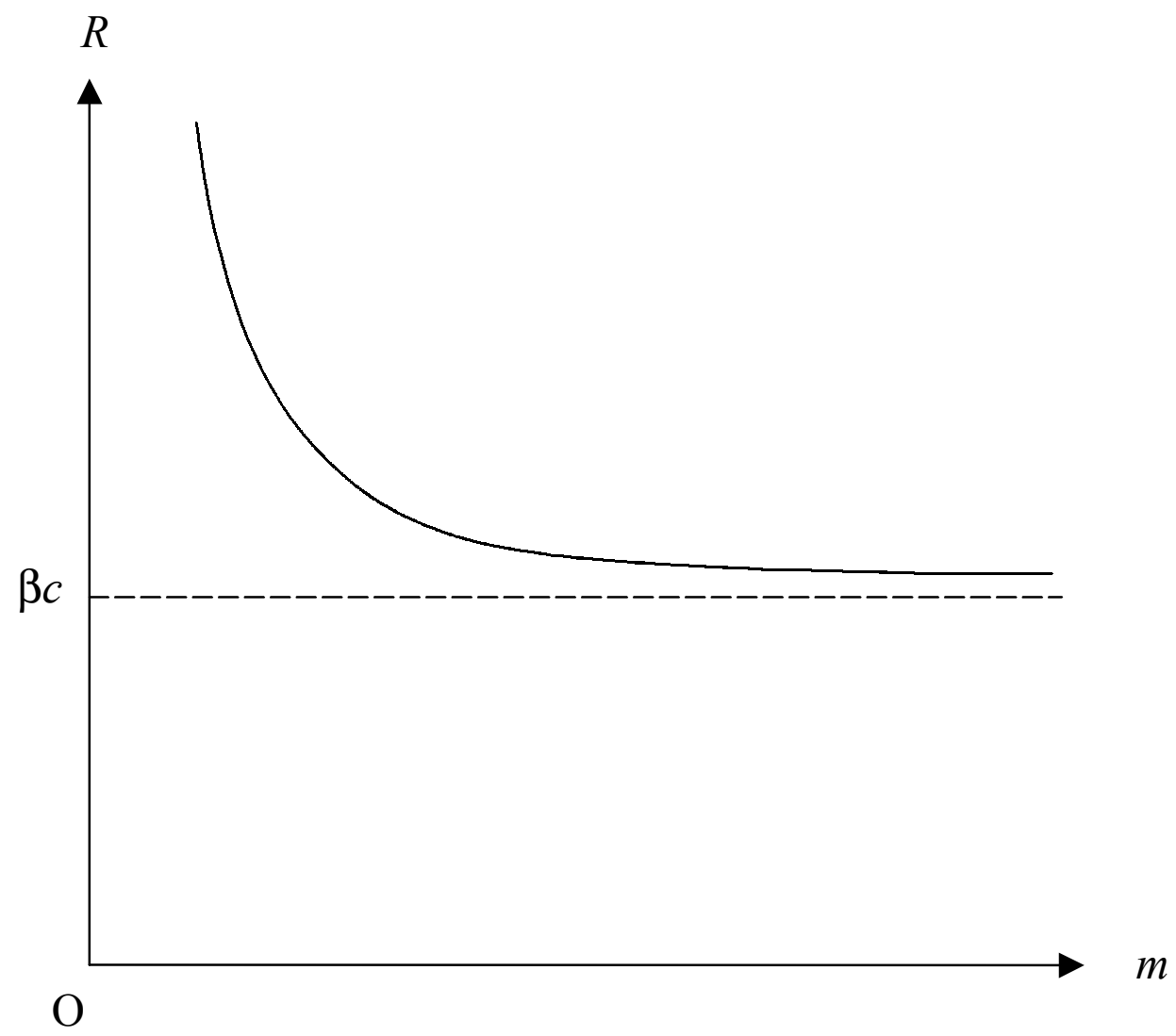

Figure 1: Money Demand with a Liquidity Trap 


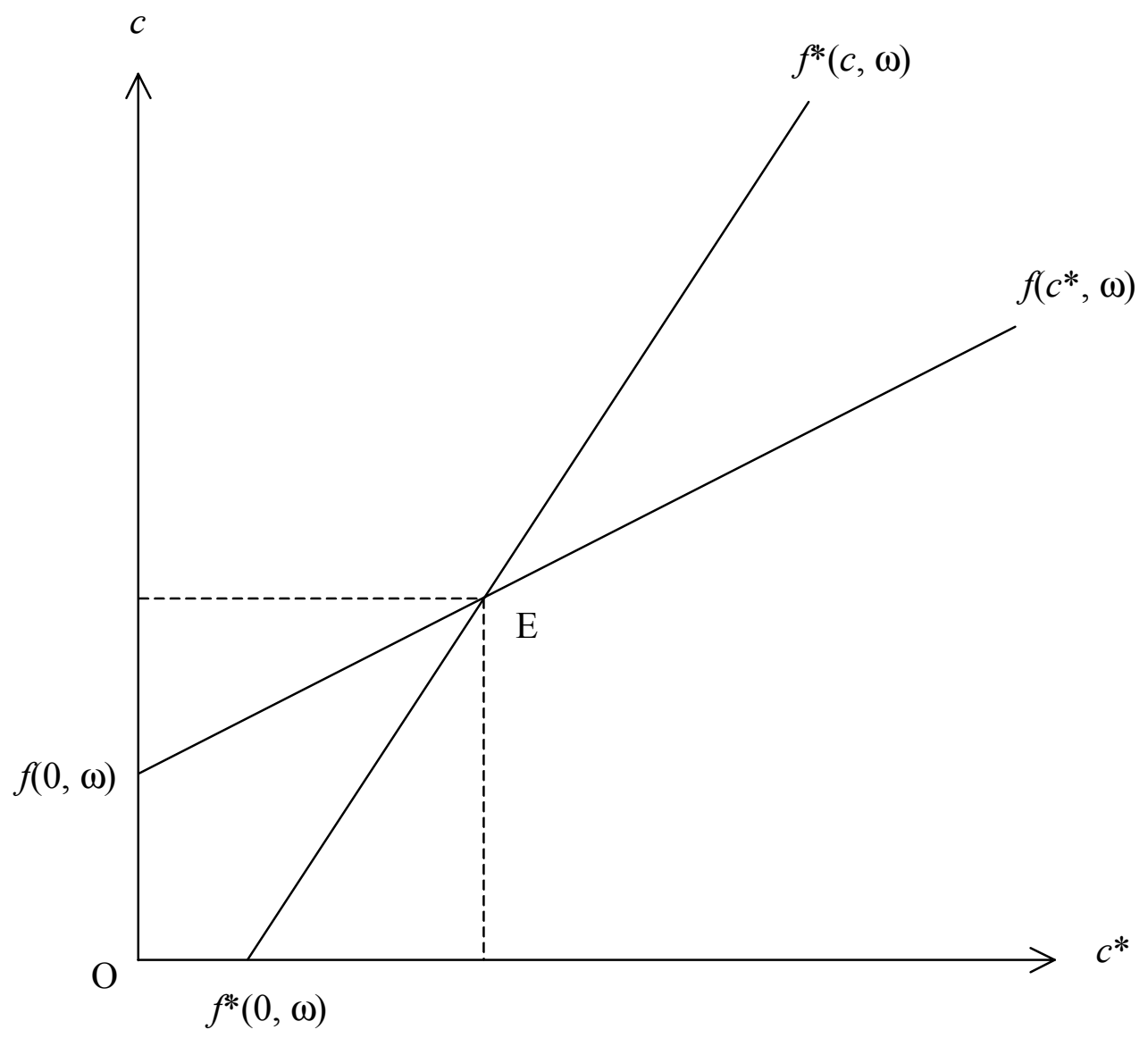

Figure 2: Interdependence of Consumption 


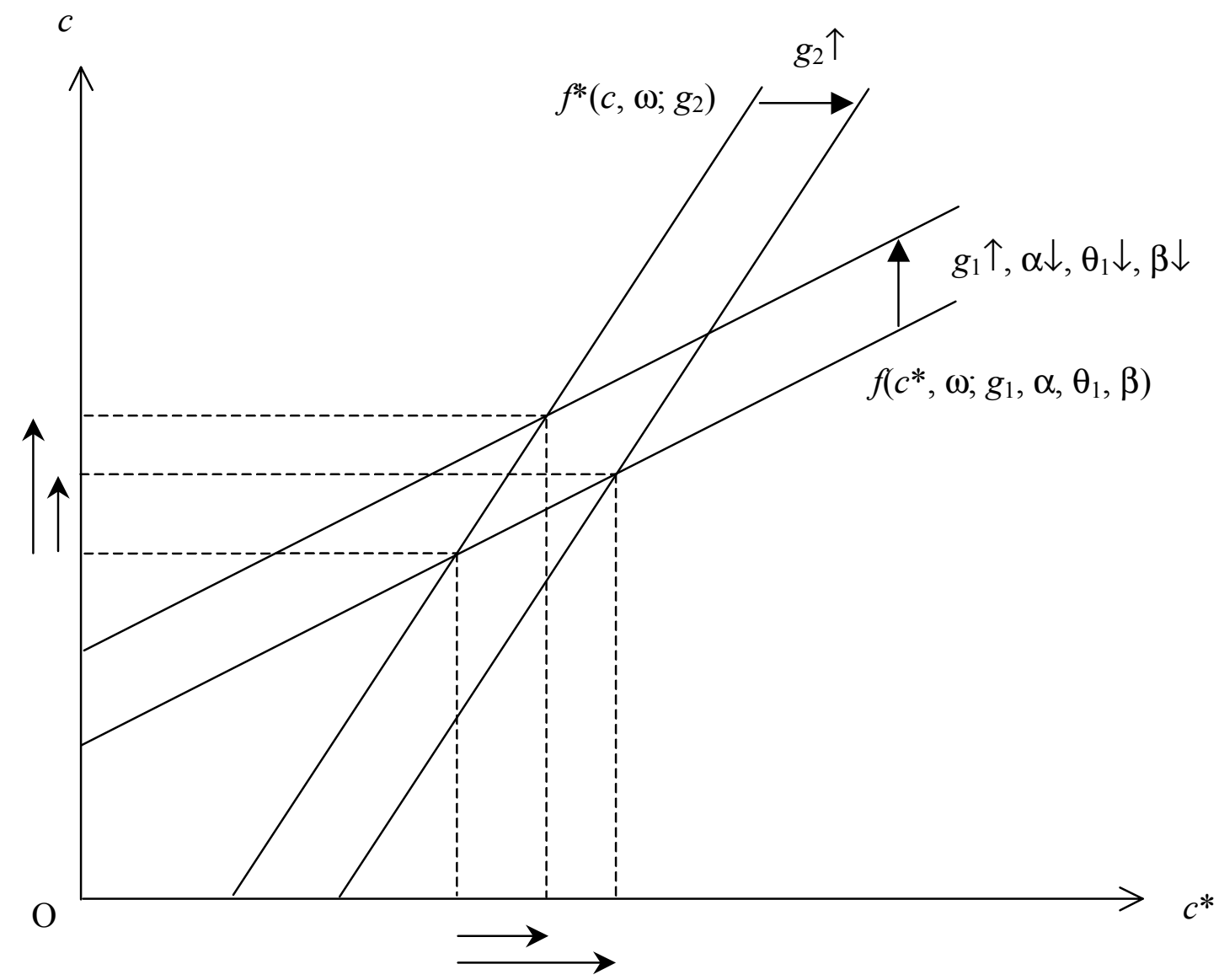

Figure 3: Mundell-Fleming Features 
Country J's Current Account ( $\dot{b}$ or $B^{P}$ )

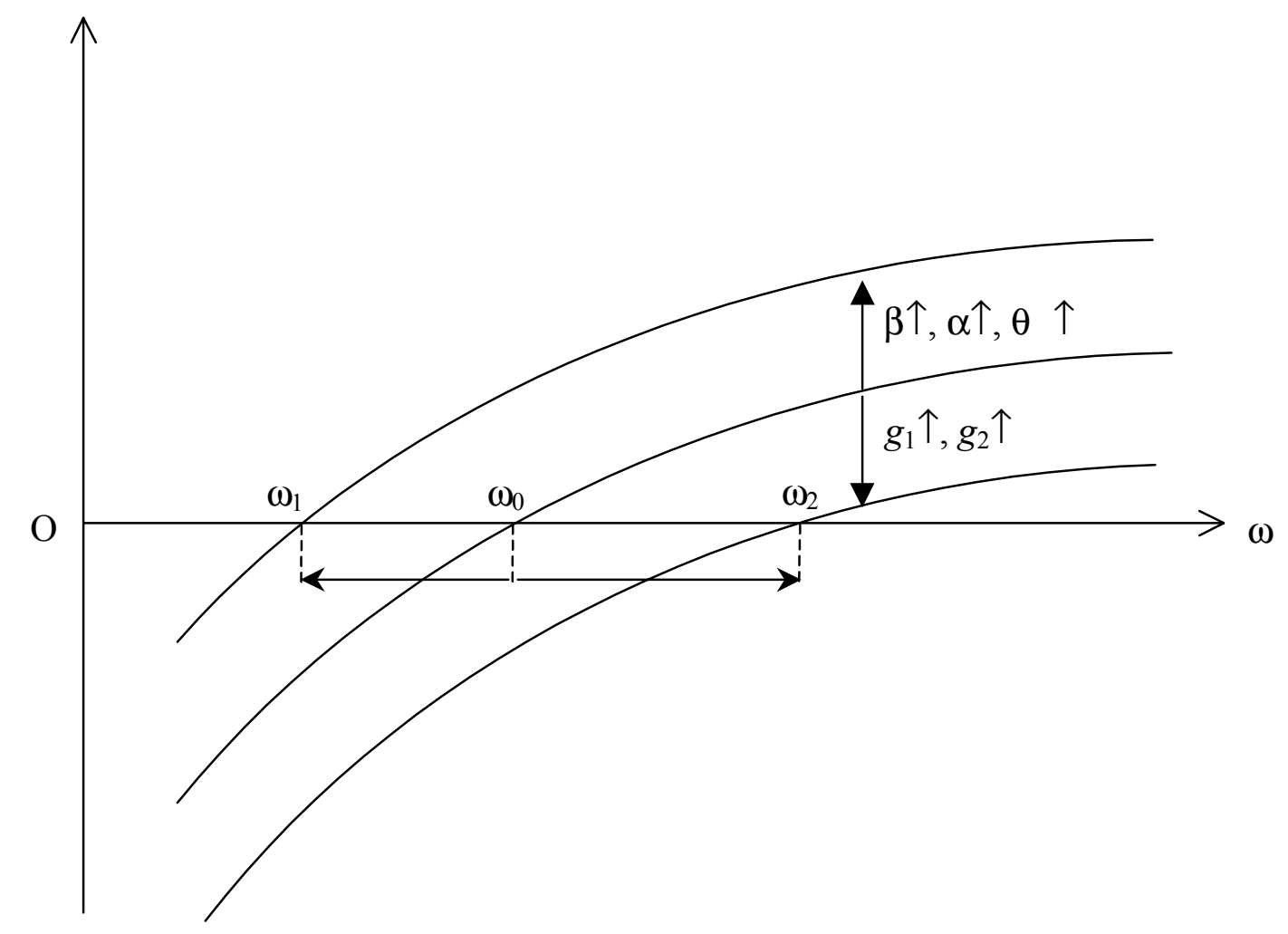

Figure 4: Current Account 